\title{
Use of In Situ Simulation to Improve Emergency Department Readiness for the COVID-19 Pandemic
}

\author{
Muna Aljahany, MD, CHSE; ${ }^{1} \odot$ Wajdan Alassaf, MD; ${ }^{1} \odot$ Ahmed A. Alibrahim, MD; ${ }^{2}$ \\ Osama Kentab, MD; ${ }^{2}$ Abdullah Alotaibi, MD; ${ }^{2}$ Abdulaziz Alresseeni, MD; ${ }^{2}$ Abdulaziz Algarni, MD; ${ }^{2}$ \\ Hamad A. Algaeed, MD; ${ }^{2}$ Mohammed I. Aljaber, MD ${ }^{3}$ Badriyah Alruwaili, MD; ${ }^{2}$ Khalid Aljohani, MD $^{2}$
}

1. College of Medicine, Princess Nourah bint Abdulrahman University, Riyadh, Saudi Arabia

2. Emergency Department, King Abdullah bin Abdulaziz University Hospital, Riyadh, Saudi Arabia

3. College of Medicine, Imam Mohammad Ibn Saud Islamic University, Riyadh, Saudi Arabia

Correspondence:

Wajdan Alassaf, MD

College of Medicine

Princess Nourah bint Abdulrahman University

Riyadh, P.O. Box 84428 KSA

E-mail: wialassaf@pnu.edu.sa

Conflicts of interest/funding: This research was funded by the Deanship of Scientific Research at Princess Nourah Bint Abdulrahman University, Riyadh, Saudi Arabia through the Fast-track Research Funding Program. The authors have no conflicts of interest to declare.

Keywords: COVID-19; emergency department; mock codes; simulation

\section{Abbreviations:}

COVID-19: coronavirus disease 2019

ED: emergency department

EMT: emergency medical technician

HCP: health care provider

PPE: personal protective equipment

RT: respiratory therapist

SARS: severe acute respiratory syndrome

WHO: World Health Organization

Received: August 22, 2020

Revised: September 26, 2020

Accepted: October 7, 2020

\section{Abstract}

Introduction: During the world-wide coronavirus disease 2019 (COVID-19) outbreak, there is an urgent need to rapidly increase the readiness of hospitals. Emergency departments (EDs) are at high risk of facing unusual situations and need to prepare extensively in order to minimize risks to health care providers (HCPs) and patients. In situ simulation is a well-known method used in training to detect system gaps that could threaten safety. Study Objectives: One objective is to identify gaps, test hospital systems, and inform necessary modifications to the standard processes required by patients with COVID-19 presenting at the hospital. The other objective is to improve ED staff confidence in managing such patients, and to increase their skills in basic and advanced airway management and proper personal protective equipment (PPE) techniques.

Methods: This is a quasi-experimental study in which 20 unannounced mock codes were carried out in ED resuscitation and isolation rooms. A checklist was designed, validated, and used to evaluate team performances in three areas: donning, basic and advanced airway skills, and doffing. A pre- and post-intervention survey was used to evaluate staff members' perceived knowledge of ED procedures related to COVID-19 and their airway management skills.

Results: A total of 20 mock codes were conducted in the ED. Overall, 16 issues that posed potential harm to staff or patients were identified and prioritized for immediate resolution. Approximately $57.4 \%$ of HCPs felt comfortable dealing with suspected/confirmed, unstable COVID-19 cases after mock codes, compared with 33.3\% beforehand ( $\mathrm{P}=.033)$. Of ED HCPs, $44.4 \%$ felt comfortable performing airway procedures for suspected/confirmed COVID-19 cases after mock codes compared with 29.6\% beforehand. Performance of different skills was observed to be variable following the 20 mock codes. Skills with improved performance included: request of chest $\mathrm{x}$-ray after intubation (88.0\%), intubation done by the most experienced ED physician (84.5\%), and correct sequence and procedure of PPE (79.0\%).

Conclusion: Mock codes identified significant defects, most of which were easily fixed. They included critical equipment availability, transporting beds that were too large to fit through doors, and location of biohazard bins. Repeated mock codes improved ED staff confidence in dealing with patients, in addition to performance of certain skills. In situ simulation proves to be an effective method for increasing the readiness of the ED to address the COVID-19 pandemic and other infection outbreaks.

Aljahany M, Alassaf W, Alibrahim AA, Kentab O, Alotaibi A, Alresseeni A, Algarni A, Algaeed HA, Aljaber MI, Alruwaili B, Aljohani K. Use of in situ simulation to improve emergency department readiness for the COVID-19 pandemic. Prehosp Disaster Med. 2021;36(1):6-13.

doi:10.1017/S1049023X2000134X

(C) The Author(s), 2020. Published by Cambridge University Press on behalf of World Association for Disaster and Emergency Medicine. This is an Open Access article, distributed under the terms of the Creative Commons Attribution-NonCommercial-NoDerivatives licence (http://creativecommons.org/licenses/by-nc$\mathrm{nd} / 4.0 /$ ), which permits non-commercial re-use, distribution, and reproduction in any medium, provided the original work is unaltered and is properly cited. The written permission of Cambridge University Press must be obtained for commercial re-use or in order to create a derivative work. 


\section{Introduction}

World-wide attention has focused on coronaviruses, owing to the discovery of a highly pathogenic human coronavirus (severe acute respiratory syndrome [SARS]-CoV-2), which was discovered in December 2019 in China and later named coronavirus disease 2019 (COVID-19). ${ }^{1}$ Since its detection, it has rapidly spread beyond China to the rest of the world. ${ }^{2}$ On March 11, 2020, the World Health Organization (WHO; Geneva, Switzerland) defined the COVID-19 situation as a pandemic and declared an international emergency. ${ }^{2,3}$ Though human coronavirus infections are typically mild, COVID-19 can cause fatal illness. ${ }^{4,5}$

The rise of COVID-19 has shown that protocols and policies for initial management need to adapt, using science-based evidence. ${ }^{6}$ Job-related stress, segregation, suspicion and fear of other people, and concerns about infection, family health, and sickly peers can create additional challenges in a pandemic. ${ }^{7} \mathrm{~A}$ heavy sense of responsibility, lack of proper personal protection equipment (PPE), shortage of certain medications, extensive media reporting, and feelings of being inadequately supported can add significantly to the psychological burden borne by health care workers. ${ }^{8,9}$ Studies have found that one-third to one-half of health care workers showed significant stress during the SARS outbreak, with those in quarantine or treating colleagues showing higher levels of distress. ${ }^{10,11}$ Medical and psychiatric management can help prevent the fear, uncertainty, and stigmatization that are commonly caused by epidemics. ${ }^{12}$

The COVID-19 pandemic has shown that continued commitment to global preparedness is essential. Previous epidemics have led to an initial increased awareness of global health, but once the initial anxiety has passed, preparedness is given a lower priority - a panic-then-forget cycle, that has yet to be broken. To break this cycle, it is essential to prioritize preparedness interventions and the requisite funding. ${ }^{13}$

A gap of preparedness was seen when there was a delay in identifying the first cases in the H1N1 pandemic, despite the fact that studies had shown that accessibility of standard operating procedures and effective training programs are effective, even though they might be complicated, time consuming, and costly. ${ }^{14}$ The benefits of previous investments in preparedness, mainly labs and data analytics capabilities, were shown when the US Centers for Disease Control and Prevention (CDC; Atlanta, Georgia USA) quickly developed a test for COVID-19. ${ }^{15}$ The earlier SARS outbreak had also highlighted the importance of training staff to work outside their area of familiarity and to have access to psychological first aid and coping assistance. ${ }^{10}$ Planning for a likely pandemic should ideally include preparing clinicians to identify and treat irregular cases of the infectious disease, as well as national preparedness for its spread. ${ }^{16}$

Simulation can help assess the capability of health care providers $(\mathrm{HCPs})$ to follow established protocols. It has revealed errors in preparedness plans in the case of an influenza pandemic. ${ }^{17} \mathrm{In}$ situ simulation involving scenarios that integrate health care workers from multiple disciplines into a clinical environment has been shown to improve preparedness for infrequent, high-risk situations. ${ }^{18}$ Simulated cases can detect gaps in preparedness plans drawn up by medical staff, and may be of great value as awareness of errors and their correction can lead to refined plans and improvements in response to any case that could presage a pandemic. ${ }^{16}$ Doctrine, infrastructure, equipment, knowledge and education of health care workers, simulation, and drills can all comprise elements of a "preparedness pyramid" to be used in mass-casualty scenarios. ${ }^{16}$ Simulation-based training has been used by many medical specialties to establish competencies in the skills essential to medical practice. It can mimic various clinical scenarios that are designed to address specific objectives, and it can integrate practical knowledge allowing trainees to assess their performance in a virtual setting wherein they can identify the areas that need improvement and build self-confidence when dealing with similar, real-life cases. ${ }^{16}$ One of the invaluable advantages of simulation is its ability to replicate rare and highly infectious disease cases in a safe, yet challenging environment without jeopardizing anyone's safety. ${ }^{19-21}$ Furthermore, a high-fidelity simulator can assess the progress of learners, from novice to expert level, in accordance with Miller's pyramid for clinical competency, which is an essential pillar of training and assessment. ${ }^{22}$

The WHO has issued guidance for the prevention and protection strategies that health care workers treating COVID-19 patients should adopt in order to protect themselves, and to prevent further transmission of the virus to other vulnerable people. ${ }^{23}$ Particularly for those performing aerosol-generating procedures, the WHO issued guidance on the required level of PPE, which includes respirators, eye protection, long-sleeved gowns, and water-resistant aprons. In addition, WHO guidelines state that the management of patients with suspected or confirmed COVID-19 should involve clear communication while minimizing the number of people in the same room. ${ }^{4}$ Many methods such as lectures, seminars, workshops, exercises, and drills have been used by health care professionals to enable them to better prepare for and manage emergencies. Drills and exercises have shown to be the most effective ways of preparing for emergencies. ${ }^{14}$

The hospital in this study is a relatively new academic hospital, and hence had no prior experience of pandemics. Additionally, some of its staff had no previous experience in dealing with influenza epidemics or pandemics. For that reason, this study was conducted with the aim of identifying defects that pose potential problems, testing the hospital's systems, and modifying its standard processes for patients with COVID-19 presenting at the emergency department (ED). Another objective was to improve the ED staff confidence in managing such patients, and to increase their skills in basic and advanced airway management, as well as knowledge of proper PPE techniques.

\section{Materials and Methods}

The study was deemed exempt from the institutional review board at Princess Nourah bint Abdulrahman University (Riyadh, Saudi Arabia; log number 20-0145). The target population was ED physicians, nurses, emergency medicine technicians (EMTs)/paramedics, and respiratory therapists (RTs).

This is a quasi-experimental study that was conducted from February through May 2020 in a hospital's ED to assess the overall performance of the entire ED team. The hospital is a 300-bed tertiary academic care center. Mangers of the ED recognized the urgent need to be prepared for COVID-19. A total of 20 unannounced mock codes were carried out in ED resuscitation and isolation rooms. Mock codes were conducted over days and nights to ensure they were experienced by all staff and in different situations. A simulated scenario that began at the main entrance with a suspected case of COVID-19 was managed until the time of intubation. The scenario began with a person playing the role of a patient who walks through the main entrance, who is replaced by a manikin (SimMan 3G; Laerdal Medical; Stavanger, Norway) once reaching the treatment room.

Mock codes were conducted by five expert emergency physicians who had prior experience of simulation training. A 20 -minute mock code was followed by around 40 minutes of a standardized debriefing 
session that discussed the reaction phase, the encounter, and concluded with a summary of those procedures that were done well and those that needed to improve (the Plus Delta method). The debriefing considered the scenario objectives: to review the triage and respiratory zone processes peculiar to COVID-19 suspected cases, donning/doffing, and airway management. The ED board was used to document what went well and things to improve. Results were immediately reviewed and recurring themes, systemic errors, and potential problems identified.

A checklist was designed to measure performance skills of random, on-duty teams. The skills fell into three categories, concerning: (1) donning, (2) basic and advanced airway skills, and (3) doffing. The checklist was reviewed by experts in emergency medicine and critical care for content validity, and was piloted with ED teams before starting the experiment. A trained observer, who is a physician certified in emergency medicine - or two observers for some mock codes scored each exercise. Different experts observed the mock code.

A survey was distributed before and after the 20 mock code drills. Addressed to ED HCPs (physicians, nurses, EMTs/paramedics, and RTs), its aim was to assess: (1) ED providers' perception of in situ simulated codes (mock codes) as a tool for preparing them to deal with COVID-19 patients; (2) their perceived level of knowledge of the hospital's triage processes for COVID-19 patients and respiratory zone flow processes for suspected or confirmed COVID-19 cases; and (3) their level of comfort when dealing with stable and unstable COVID-19 patients and their performance of airway procedures on those patients. Before starting the experiment, the survey was reviewed for its content validity by four experts from emergency medicine, piloted with ED staff, then modified to take into account their comments.

\section{Statistical Analysis}

The two sets of questionnaires were coded and the data collected were entered into Excel files (Microsoft Corp.; Redmond, Washington USA). All categorical variables were presented as frequencies and percentages, while continuous variables were presented means ( $95 \%$ confidence interval). In the checklist file, an overall performance score was calculated as the sum of the mock codes' evaluation of 22 skills, with two points recorded if the item was performed, one point recorded if the item was partially performed, and zero points if the item was not performed. As the maximum score was two per item, and 44 for all items, individual and overall scores were transformed into a 100-point scale for easy interpretation. Differences in performance score according to the characteristics of mock codes and expert evaluators were examined using the Mann-Whitney test. Differences in performance score over consecutive mock codes were examined using the Jonckheere-Terpstra trend test. In the survey file, responses of the HCPs to survey questions before and after attending the mock codes were examined using the McNemar-Bowker test. Additionally, the changes in the survey outcomes (knowledge and confidence of $\mathrm{HCPs}$ ) subsequent to experiencing the mock codes were examined according to the characteristics of HCPs using Fisher's exact test for categorical change and the KruskalWallis test for percentage change. The latter indicates the average number of items that improved, relative to all six items evaluated, with a positive percentage indicating improvement and a negative percentage indicating worsening. All $\mathrm{P}$ values were two-tailed. $\mathrm{P}$ values $<.05$ were considered significant. SPSS software (release 23.0; IBM Corp; Armonk, New York USA) was used for all statistical analyses.

\section{Results}

A total of 14 evaluators assessed 22 skills performed by HCPs during 20 COVID-19 mock codes conducted at the ED of the hospital. The skills checklist had a high reliability with Cronbach's Alpha of 0.794. As shown in Table 1 and Figure 1, a wide range of differences in the performance of different skills was observed, with an average performance of $59.2 \%$. Skills with better than $70.0 \%$ performance included: request for chest x-ray (88.0\%); intubation done by the most experienced ED physician (84.5\%); correct sequence and procedure of PPE with hand hygiene (79.0\%); re-auscultation to confirm the tube position (74.0\%); and pre-oxygenation with $\mathrm{O}_{2}$ flows $<6 \mathrm{~L} /$ minute for five minutes, with correct face mask selection (71.0\%). Skills with worse than $40.0 \%$ performance included: considering early conversion to laryngeal mask airway in case of ventilation difficulty (19.5\%); using closed suctioning system and standby ventilator while suctioning in case suctioning is required (28.0\%); keeping nasal cannula at $5 \mathrm{~L} /$ minute for apneic oxygenation (35.0\%); and standby ventilator before removal of face mask for intubation $(35.0 \%)$.

Twelve $(60.0 \%)$ mock codes were performed in the resuscitation room and eight (40.0\%) in the isolation room with no difference in performance according to mock code location $(\mathrm{P}=.593)$. A total of $13(65.0 \%)$ mock codes were evaluated by two evaluators and seven (35.0\%) mock codes were evaluated by one evaluator with no difference in performance according to the number of evaluators $(\mathrm{P}=.947)$. Approximately $64.3 \%$ of evaluators were male, with male evaluators performing better in mock codes than female evaluators $(66.4 \%$ $[\mathrm{SD}=11.7 \%]$ versus $48.4 \%[\mathrm{SD}=19.5 \%] ; \mathrm{P}=.005)$. Figure 2 shows a significant trend of improving performance with an increase in the consecutive number of mock codes $(\mathrm{P}<.001)$. For example, the first five mock codes showed a performance level of less than $40.0 \%$ while the second-half of mock codes showed performance levels ranging between $55.7 \%$ and $79.5 \%$.

As shown in Table 2, the majority of HCPs working in the ED of the hospital who participated in the COVID-19 mock codes were emergency nurses $(64.8 \%)$, followed by emergency physicians (20.4\%), paramedics/EMTs (9.3\%), and finally RTs (5.6\%). Experience ranged from between a few months to 30 years, with an average of $8.2(\mathrm{SD}=5.5)$ years. Approximately $59.3 \%$ of HCPs had previous experience in dealing with communicable diseases (eg, MERS-CoV and SARS) and only 37.0\% attended any in situ simulation mock codes for COVID-19.

Health care providers responded to the survey questions before and after intervention. Only one of six items showed significant improvement after attending mock codes. Approximately 57.4\% HCPs felt comfortable dealing with suspected/confirmed, unstable COVID-19 cases after mock codes compared with 33.3\% before mock codes $(\mathrm{P}=.033)$. Additionally, $44.4 \%$ of HCPs felt comfortable performing airway procedures for suspected/confirmed COVID-19 cases after mock codes compared with $29.6 \%$ before mock codes, but the difference did not reach statistical significance $(\mathrm{P}=.062)$. The remainder of the items did not change appreciably after mock codes. For example, $61.1 \%$ of HCPs before mock codes, and $66.7 \%$ after mock codes, believed that they had a good knowledge level of the hospital ED triage processes for suspected/confirmed COVID-19 cases $(\mathrm{P}=.581)$. Feeling comfortable dealing with suspected/confirmed, unstable COVID-19 cases showed the highest improvement (24.1\%), while having a good knowledge level of the ED triage process had the lowest improvement (3.7\%).

Emergency nurses and HCPs with moderate experience had the greatest improvement in perceived knowledge and confidence 


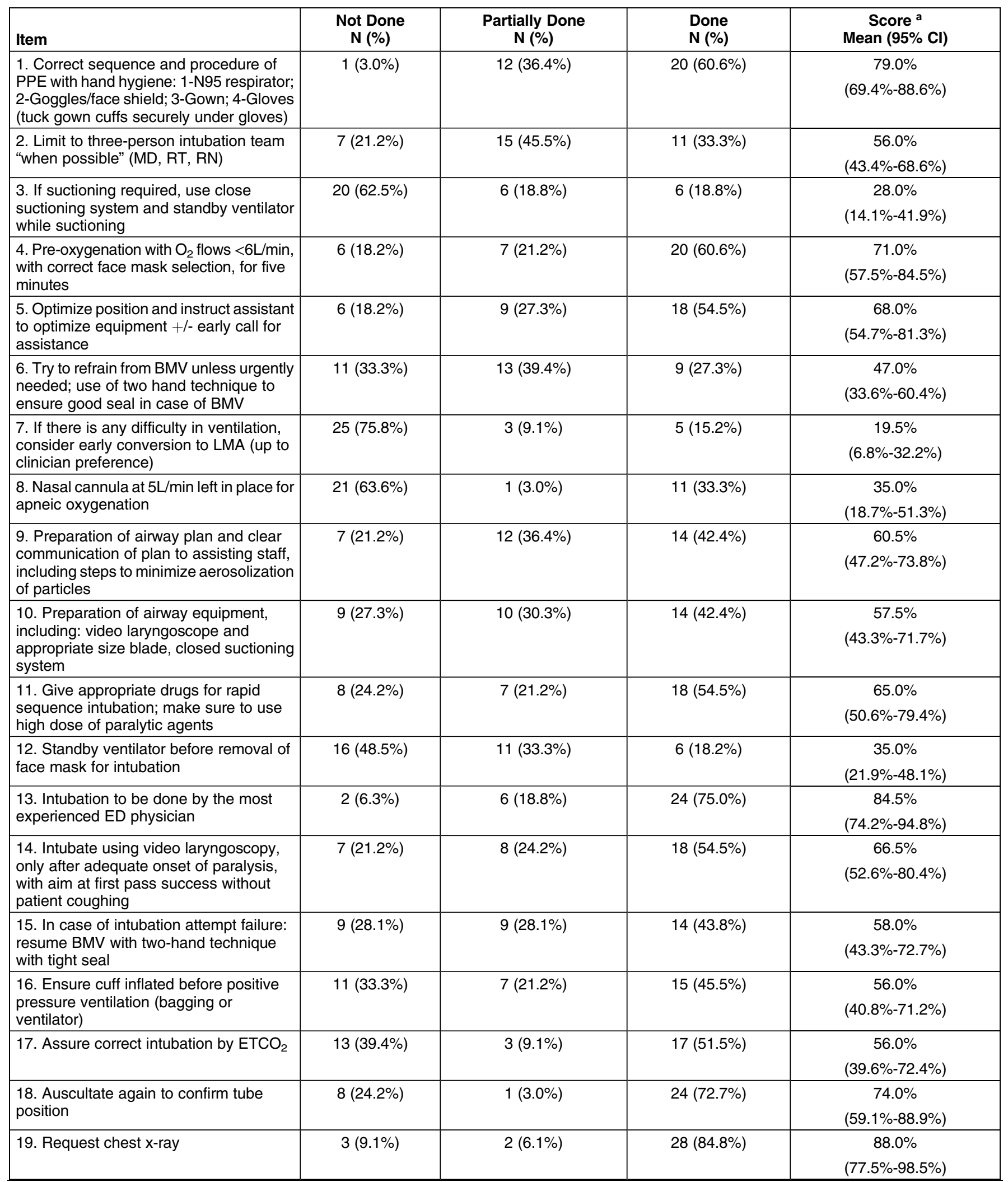

Aljahany ๑ 2021 Prehospital and Disaster Medicine

Table 1. Evaluation of the Performance of 22 Skills during 20 Mock Codes for Managing Suspected Cases of COVID-19 at the Hospital ED (continued) 


\begin{tabular}{|c|c|c|c|c|}
\hline Item & $\begin{array}{l}\text { Not Done } \\
\text { N (\%) }\end{array}$ & $\begin{array}{l}\text { Partially Done } \\
\text { N (\%) }\end{array}$ & $\begin{array}{l}\text { Done } \\
\text { N (\%) }\end{array}$ & $\begin{array}{c}\text { Score }^{a} \\
\text { Mean }(95 \% \mathrm{Cl})\end{array}$ \\
\hline $\begin{array}{l}\text { 20. Follow gown down steps correctly and } \\
\text { appropriately: 1-Remove gloves; } 2- \\
\text { Remove (top) cap and eye protection; 3- } \\
\text { Remove gown; 4-remove mask; 5- } \\
\text { remove particulate respirator }\end{array}$ & $4(12.1 \%)$ & $13(39.4 \%)$ & $16(48.5 \%)$ & $\begin{array}{c}68.0 \% \\
(56.0 \%-80.0 \%)\end{array}$ \\
\hline 21. Perform hand hygiene & $11(33.3 \%)$ & $5(15.2 \%)$ & $17(51.5 \%)$ & $\begin{array}{c}59.0 \% \\
(43.3 \%-74.7 \%)\end{array}$ \\
\hline $\begin{array}{l}\text { 22. Proper disposal of used consumables } \\
\text { and equipment }\end{array}$ & $6(18.2 \%)$ & $8(24.2 \%)$ & $19(57.6 \%)$ & $\begin{array}{c}69.5 \% \\
(56.1 \%-82.9 \%) \\
\end{array}$ \\
\hline Overall Performance Score & $211(29.2 \%)$ & $168(23.2 \%)$ & $344(47.6 \%)$ & $\begin{array}{c}59.2 \% \\
(53.3 \%-65.0 \%)\end{array}$ \\
\hline
\end{tabular}

Table 1. Evaluation of the Performance of 22 Skills during 20 Mock Codes for Managing Suspected Cases of COVID-19 at the Hospital ED (continued).

Abbreviations: BMV, bag mask ventilation; ED, emergency department; LMA, laryngeal mask airway; MD, medical doctor; PPE, personal protective equipment; RN, registered nurse; RT, respiratory therapist.

${ }^{a}$ Higher score means better performance. Individual score was calculated as the sum of evaluation with two points recorded if the item was done, one point recorded if the item was partially done, and zero points recorded if the item was not done. The percentage represents observed score (actual performance) relative to maximum possible score (best performance).

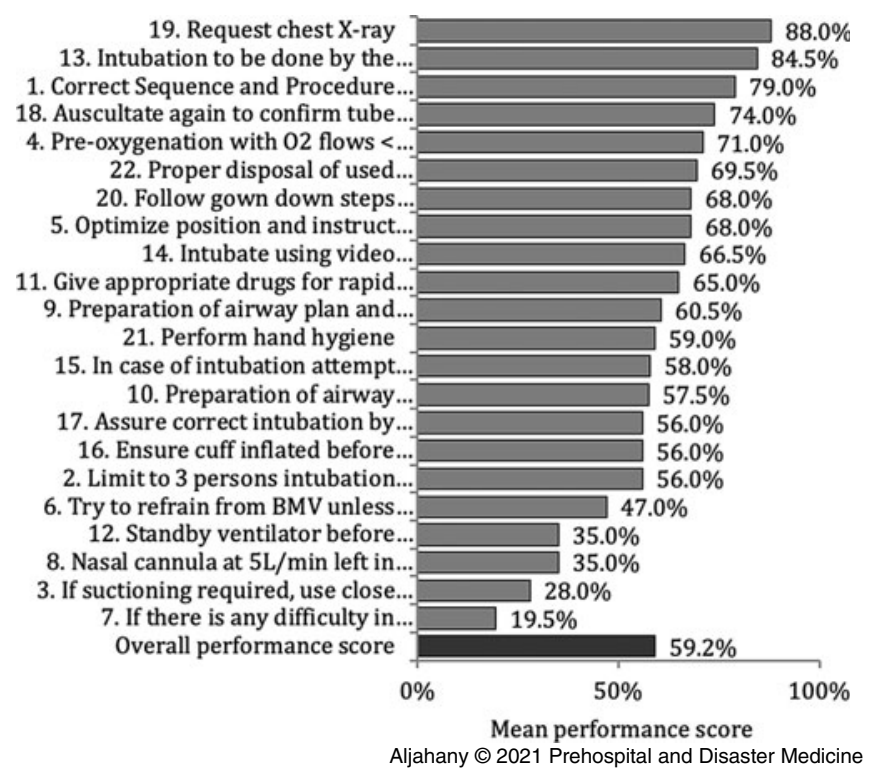

Figure 1. Evaluation of the Performance of 22 Skills during 20 Mock Codes for Managing Suspected Cases of COVID-19 at Hospital Emergency Department.

dealing with COVID-19 cases after attending COVID-19 mock codes $(15.7 \%$ and $23.5 \%$, respectively). The difference was approaching significance for nurses $(\mathrm{P}=.060)$ but not significant for experience $(\mathrm{P}=.481)$.

\section{Discussion}

The hospital ED staff were not prepared for the new requirement of dealing with sick patients with suspected/confirmed COVID-19, which would be expected given that $40.7 \%$ of the hospital staff had no prior experience with communicable diseases. As was found before intervention, only $33.3 \%$ felt comfortable dealing with suspected/confirmed, unstable COVID-19 cases before mock codes.
This number jumped to $57.4 \%$ after mock codes $(\mathrm{P}=.033)$. In another study, of the participants in the training who consisted of more than 1,250 hospital staff, $76.0 \%$ felt better able to cope after the session, compared with only $35.0 \%$ who felt prepared to deal confidently with the pandemic before the training. ${ }^{7}$

The small improvement in perceived knowledge of ED processes related to COVID-19 patients subsequent to the mock codes (66.7\% compared to $61.1 \%$ ) could be explained by the fact that there was less emphasis on ED processes and discussion during debriefing compared to other objectives. However, when results are analyzed by profession, ED nurses showed a greater improvement (15.7\%) in perceived knowledge and confidence dealing with COVID-19 cases after attending the COVID-19 mock codes.

The performance of teams, as measured by the previously described checklist, was variable (Figure 1). However, the overall team performance was improving over time. In the first five mock codes, performance was less than $40.0 \%$, while during the secondhalf of the mock codes, performance ranged between $55.7 \%$ and $79.5 \%$ with a significant $\mathrm{P}$ value $(\mathrm{P}<.001)$, as shown in Figure 2. One of the critical items that showed significant improvement over time was correct sequence and procedure of PPE with hand hygiene (79.0\%). Abualenain, et al described a similar finding in a study using simulation-based training for Ebola PPE for HCPs. ${ }^{24}$ They found that simulation-based training improved performance of HCPs on a PPE checklist from $37.0 \%$ to $86.0 \%$. They ended their study with a conclusion that high-fidelity simulation is effective and practical for training HCPs on the use of PPE. ${ }^{24}$

Interestingly, performance in the current study did not change with location (resuscitation or isolation room), regardless of the fact that teams were hesitant to treat sick patients in an isolation room, which had never previously been undertaken. Size of the room did not affect the entrance of the ventilator, crash cart, or x-ray machine, as had been assumed. Similar findings were reported in a study measuring cardiopulmonary resuscitation outcomes before and after mock codes that were carried out in different units of the hospital. It reported no significant differences based on location. ${ }^{25}$ Another interesting finding is the higher performance in 


\begin{tabular}{|c|c|c|}
\hline & Number ${ }^{a}$ & Percentage \\
\hline \multicolumn{3}{|l|}{ Professional Category } \\
\hline Emergency Physician & 11 & $20.4 \%$ \\
\hline Emergency Nurse & 35 & $64.8 \%$ \\
\hline Respiratory Therapist & 3 & $5.6 \%$ \\
\hline Paramedic/Emergency Medicine Technician & 5 & $9.3 \%$ \\
\hline \multicolumn{3}{|l|}{ Years of Experience } \\
\hline Mean (SD) & $8.2(\mathrm{SD}=5.5)$ & \\
\hline$\leq 5$ & 17 & $31.5 \%$ \\
\hline $6-10$ & 22 & $40.7 \%$ \\
\hline$>10$ & 15 & $27.8 \%$ \\
\hline \multicolumn{3}{|c|}{$\begin{array}{l}\text { Previous Experience in Dealing with Communicable Diseases (eg, MERS-CoV } \\
\text { or SARS) }\end{array}$} \\
\hline No & 22 & $40.7 \%$ \\
\hline Yes & 32 & $59.3 \%$ \\
\hline
\end{tabular}

Table 2. Characteristics of the Health Care Providers Working at the Hospital ED

Abbreviations: ED, emergency department; SARS, severe acute respiratory syndrome.

a Unless mentioned otherwise.

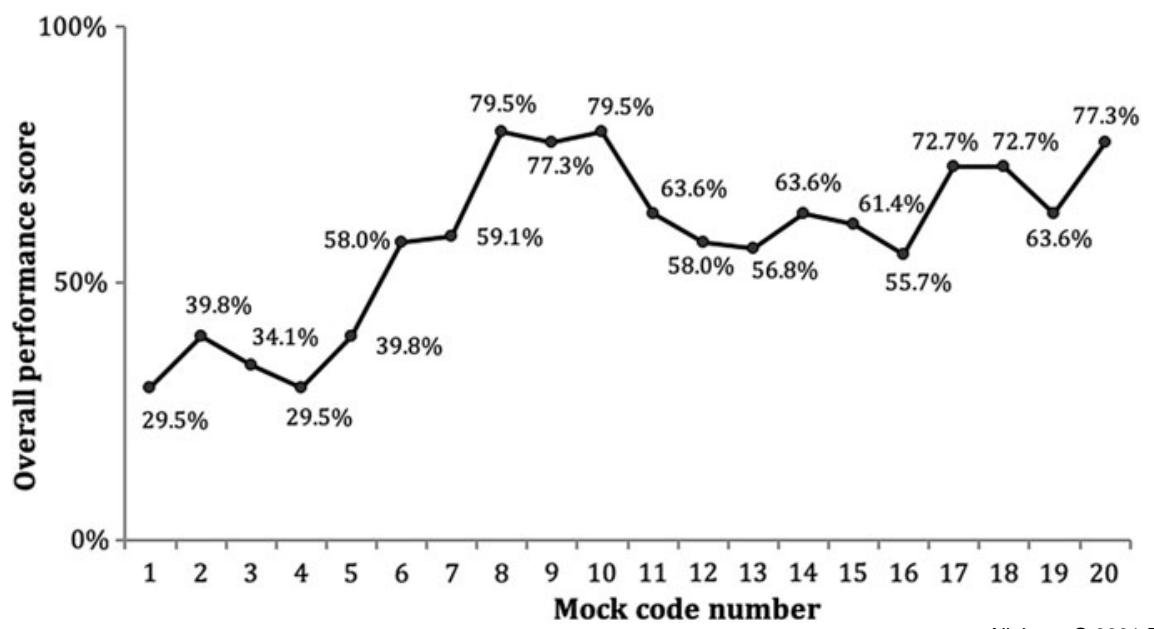

Figure 2. Overall Performance Score during 20 Mock Codes for Managing Suspected Cases of COVIrospital and Disaster Medicine Department.

Note: The trend was significantly increasing $(\mathrm{P}=.001$ using Jonckheere-Terpstra test).

mock codes with male evaluators compared with female evaluators $(66.4 \%[\mathrm{SD}=11.7 \%]$ versus $48.4 \%[\mathrm{SD}=19.5 \%] ; \mathrm{P}=.005)$. This can perhaps be partially explained by the gender bias in evaluations that has been shown in literature, though not consistently. ${ }^{26}$

In addition to the above-mentioned benefits of in situ simulation, additional benefits of detecting defects and safety threats were exhibited. These defects were generally similar to the findings of another in situ simulation study done in an intensive care unit to measure readiness for COVID-19 patients. ${ }^{4}$ Another study done by Lababidi, et al described the authors' experience of simulating a full-scale disaster drill in a big tertiary hospital to test preparedness of HCPs for a COVID-19 outbreak. ${ }^{27}$

Their debriefing report recommended reinforcing PPE training and ensuring the availability of different sizes of PPE. ${ }^{26}$ Some defects were significant, such as critical equipment availability and the transporting of beds that were too wide to fit through doors, while others were simple and easy to fix, such as the location of biohazard bins. A list of examples of defects identified during the mock codes and immediate correctives measures taken is shown in Table 3.

\section{Limitations}

Conducting multiple, unannounced mock codes in clinical areas, especially crowded areas such as EDs, is challenging and prone to many factors that might affect the applicability of such a mock codes program. As the study was quasi-experimental, there is also potential limitation of generalizability of results.

Scheduling ED staff and grouping them into fixed teams was not feasible, which limited the measurement of individual team or individual subgroup performance. The observed improvement in team performance could be partly due to directives given on how to care for and manage the protocols of COVID-19 


\begin{tabular}{|c|c|}
\hline Identified Defects & Corrective Measures \\
\hline $\begin{array}{l}\text { Transporting suspected COVID-19 patient pathway was through a room } \\
\text { that has patients at the time of transfer }\end{array}$ & Assign that room as a passage and never use to assess patients \\
\hline $\begin{array}{l}\text { Wheelchair and bed for transport too big to pass through one of the doors } \\
\text { in respiratory pathway }\end{array}$ & Smaller wheelchairs and stretchers were provided for transport \\
\hline $\begin{array}{l}\text { Mixing of patients (respiratory and non-respiratory) was noted when } \\
\text { eyeball nurse leaves his/her position to escort a patient to vital signs } \\
\text { room }\end{array}$ & Back up nurse (two nurses for eyeballing) \\
\hline Ante-room for isolation was missing certain sizes of N95, face shields & Provide the missing sizes of N95, face shields \\
\hline Only one $\mathrm{O}_{2}$ port available in isolation rooms & Provide $\mathrm{O}_{2}$ cylinder in the area for cases when two ports are needed \\
\hline Wall-mounted suction in isolation room was not working & Fixation requested \\
\hline $\begin{array}{l}\text { Biohazard bin for disposing of the gown and gloves was outside the } \\
\text { patient room }\end{array}$ & $\begin{array}{l}\text { Biohazard bins were pushed inside patient room, as per hospital infection } \\
\text { control policy }\end{array}$ \\
\hline $\begin{array}{l}\text { Communication from inside the isolation room was difficult; someone } \\
\text { must come out }\end{array}$ & $\begin{array}{l}\text { Communication through zello (a push-to-talk, Wi-Fi-based application) } \\
\text { from inside the room to the runner nurse }\end{array}$ \\
\hline $\begin{array}{l}\text { Glidescope Stylet in resus was missing and it took significant time to get } \\
\text { from another room }\end{array}$ & Include in daily checklist of resuscitation room \\
\hline Some physicians were only trained on laryngoscope, not Glidescope & Orient and train all physicians on Glidescope \\
\hline $\begin{array}{l}\text { Proper sequence of donning and doffing was not followed by all team } \\
\text { members }\end{array}$ & $\begin{array}{l}\text { Train and post a big clear picture of donning and doffing techniques in } \\
\text { areas of PPE }\end{array}$ \\
\hline Only Respiratory Therapist knows location of ventilator & Keep ventilator stationed on standby at same place \\
\hline $\begin{array}{l}\text { Yellow gowns easily torn while EMTs move patient for transportation, } \\
\text { blue gown (limited stock) }\end{array}$ & Allow use of blue gowns for transportation \\
\hline $\begin{array}{l}\text { Patients in isolation sent to } x \text {-ray suite though portable } x \text {-ray machines } \\
\text { can fit inside isolation rooms when tested }\end{array}$ & Perform $\mathrm{x}$-ray in room, no transfer to $\mathrm{x}$-ray suite \\
\hline $\begin{array}{l}\text { Use of acrylic intubation box caused significant delay in intubation } \\
\text { process, owing to new environment in one of the mock codes }\end{array}$ & Stop use of the box till further training \\
\hline $\begin{array}{l}\text { Owing to rapid changes in guidance and chance of spreading infection } \\
\text { when starting } \mathrm{O}_{2} \text { on COVID-19, delay and hesitancy were noted in } \\
\text { starting } \mathrm{O}_{2} \text { therapy when needed in scenario }\end{array}$ & Draw attention to this, and thoroughly discuss concerns during debriefing \\
\hline
\end{tabular}

Table 3. Examples of Defects Identified during Mock Codes and Corrective Measures Taken After Simulation Mock Codes Abbreviations: EMT, emergency medical technician; PPE, personal protective equipment.

patients. However, no major interventions or training programs were introduced to ED staff during the few months of this study.

\section{Conclusion}

In situ simulation is a vital task, regardless of constraints imposed by time and place, as it is clear that being prepared for pandemics is of utmost importance. Such preparation, done in a safe environment, helps establish the performance of the different units, as has been shown in the case of the hospital's ED department, where in situ simulation mock codes were able to identify the most common safety threats. Repeated mock codes showed improvements in ED staff confidence in dealing with suspected or confirmed COVID-19 patients. In situ simulation is found to be an effective method for increasing the readiness of EDs to deal with the COVID-19 pandemic and other infectious outbreaks. The effect of those mock codes on ED patient outcomes, however, has not been much studied and is an important area for future research.

\section{Acknowledgment}

The authors would like to thank ED physicians, nurses, EMT/paramedics, and RTs at the King Abdullah bin Abdulaziz University Hospital (KAAUH; Riyadh, Saudi Arabia) for their participation and incredible enthusiasm. The authors also acknowledge the support of the KAAUH senior management for simulation training.

\section{References}

1. Opriessnig T, Huang YW. Coronavirus disease 2019 (COVID-19) outbreak: could pigs be vectors for human infections? Xenotransplantation. 2020;27(2):e12591.

2. Bedford J, Enria D, Giesecke J, et al. COVID-19: towards controlling of a pandemic. Lancet. 2020;395(10229):1015-1018.

3. Neher RA, Dyrdak R, Druelle V, et al. Potential impact of seasonal forcing on a SARSCoV-2 pandemic. Swiss Medical Weekly. 2020;150:w20224.

4. Fregene TE, Nadarajah P, Buckley JF, et al. Use of in situ simulation to evaluate the operational readiness of a high-consequence infectious disease intensive care unit. Anaesthesia. 2020;75(6):733-738.

5. Huang C, Wan, Y, Li X, et al. Clinical features of patients infected with 2019 novel coronavirus in Wuhan, China. Lancet. 2020;395(10223):497-506.

6. Schuchat A, Bell BP, Redd SC. The science behind preparing and responding to pandemic influenza: the lessons and limits of science. Clin Infect Dis. 2011;52(suppl_1): S8-S12.

7. Aiello A, Khayeri MY, Raja S, et al. Resilience training for hospital workers in anticipation of an influenza pandemic. J Contin Educ Health Prof. 2011;31(1): 15-20.

8. Lai J, Ma S, Wang Y, et al. Factors associated with mental health outcomes among health care workers exposed to coronavirus disease 2019. JAMA Netw Open. 2020;3(3):e203976

9. Gaeta C, Brennessel R. COVID-19: emergency medicine physician empowered to shape perspectives on this public health crisis. Cureus. 2020;12(4):e7504 
10. Maunder RG, Leszcz M, Savage D, et al. Applying the lessons of SARS to pandemic influenza: an evidence-based approach to mitigating the stress experienced by health care workers. Can J Public Health. 2008;99(6):486-488.

11. Daugherty EL, Carlson AL, Perl TM. Planning for the inevitable: preparing for epidemic and pandemic respiratory illness in the shadow of H1N1 influenza. Clinical Infectious Diseases. 2010;50(8):1145-1154.

12. Park SC, Park YC. Mental health care measures in response to the 2019 novel coronavirus outbreak in Korea. Psychiatry Investig. 2020;17(2):85-86.

13. Jacobsen, KH. Will COVID-19 generate global preparedness? Lancet. 2020;395(10229):1013-1014.

14. Adini B, Goldberg A, Cohen R, Bar-Dayan Y. Impact of pandemic flu training on ability of medical personnel to recognize an index case of avian influenza. Eur $J$ Public Health. 2012;22(2):169-173.

15. Smith N, Fraser M. Straining the system: novel coronavirus (COVID-19) and preparedness for concomitant disasters. Am J Public Health. 2020. Epub ahead of print.

16. Leiba A, Dreiman N, Weiss G, et al. The effectiveness of an educational intervention on clinicians' knowledge of pandemic influenza. Isr Med Assoc J 2010;12(8):460-462.

17. Cardenosa N, Domínguez A, Carratalà J, et al. Usefulness of simulated cases for assessing pandemic influenza preparedness plans. Clinical Microbiology and Infection. 2010;16(9):1364-1367.

18. Fent G, Blythe J, Farooq O, Purva M. In situ simulation as a tool for patient safety: a systematic review identifying how it is used and its effectiveness. BMJ Simul Technol Enhanc Learn. 2015;1(3).
19. Lateef F. Simulation-based learning: just like the real thing. J Emerg Trauma Shock. 2010;3(4):348-352.

20. Jones F, Passos-Neto CE, Braghiroli OF. Simulation in medical education: brief history and methodology. Principles and Practice of Clinical Research. 2015;1(2).

21. Munshi F, Lababidi H, Alyousef S. Low- versus high-fidelity simulations in teaching and assessing clinical skills. Journal of Taibah University Medical Sciences. 2015;10.

22. Lopreiato JO, Downing D, Gammon W. Health care simulation dictionary. Society for Simulation in Healthcare. 2016. http://www.ssih.org/dictionary. Accessed June 17, 2020.

23. Peng PWH, Ho PL, Hota SS. Outbreak of a new coronavirus: what anesthetists should know. Br J Anaesth. 2020;124(5):497-501.

24. Abualenain JT, Al-Alawi MM. Simulation-based training in Ebola personal protective equipment for health care workers: experience from King Abdulaziz University Hospital in Saudi Arabia. J Infect Public Health. 2018;11(6): 796-800.

25. Clarke SO, Julie IM, Yao AP, et al. Longitudinal exploration of in situ mock code events and the performance of cardiac arrest skills. BMJ Simul Technol Enhanc Learn. 2019;5(1):29-33.

26. Rand VE, Hudes ES, Browner WS, Wachte RM, Avins AL. Effect of evaluator and resident gender on the American Board of Internal Medicine evaluation scores. Journal of General Internal Medicine. 1998;13(10):670-674.

27. Lababidi HMS, Alzoraigi U, Almarshed AA, et al. Simulation-based training program and preparedness testing for COVID-19 using system integration methodology. BMJ Simul Technol Enhanc Learn. 2020. Epub ahead of print. 